\title{
The use of Mental Health Review Tribunals
}

\author{
Miranda Shah and Femi Oyebode
}

Three hunctred and mily-six potients admilted under sections of tho Mentol Hectth Act (1983) were studied. One hundred and twenty-etx (35\%) patients appecied againet their detentions and 52 of these appects were heard. Only 18 patients were discharged from thelr detentions by the Tribunal in the study perlod. Younger patients were more ilkely to appeal and no potient whose firet language was not Enclith appealed in the study pertod. The titbuncls coppecer to be a fair system once the opportunity to coppeal is token up.

Patients detained under the Mental Health Act (1983) have a right to appeal to the Mental Health Review Tribunal (MHRT), whose role it is to determine whether it continues to be appropriate to detain the patient. Applications to the MHRT have risen dramatically since 1983 and in 1993 the number was approaching 10000 appeals, almost a three-fold increase since 1984 and costing about 12 million pounds (Blumenthal \& Wessely, 1994).

There have been only a handful of studies into the use and effectiveness of the MHRT. In one study only $25 \%$ of those detained appealed against their detention on Section 2 of the Act and those who appealed were more likely to be educated to at least A-level standard (Bradley et al, 1995). This may indicate that the appeal system is not equally accessible to all patients or that the patients' right to appeal is not adequately explained to the less educated patients. Furthermore, it has been shown that the decisions of the tribunals are influenced greatly by the recommendations of the responsible medical officer (RMO). Indeed, in $86 \%$ of occasions the tribunal's decision reflected the RMO's advice. However, the RMO's recommendations were not entirely dependent on the facts of the patient's circumstances but were influenced by views on the particular case as well as by previous experience with other cases (Peay. 1989). Further, male patients are more likely to be discharged by the tribunals (Saad \& Sashidharan, 1992). Thus, factors unrelated to the best interests of the patient may influence the tribunal's decision whether or not to discharge the patient from detention.
The timing of tribunals has come under the scrutiny of the Councll on Tribunals, a body set up to review the constitution and workings of tribunals. Several factors contribute to delayed tribunal hearings and include poor administrative practices, and late submission of reports by RMOs and other partles (Kaplan, 1995). These delays represent another potential failing in the protection of a patient's liberty. However, there is clearly a cost, not necessarlly monetary, incurred by RMOs and social workers in the preparation of reports for MHRTs (Malcolm, 1994) and there are cases where an MHRT may not be in the best interests of the patient (McCloughlin, 1995).

The appeal procedure is a complex and multistage process, and to investigate the system fully is outside the confines of a single study. The aim of this study was to investigate differences in the characteristics of patients detained under the Mental Health Act (1983) who appeal against the detention compared with those who do not appeal. In addition, we investigated the differences between patlents whose appeals were heard by the MHRT and those not heard. The characteristics of those patients discharged by the MHRT were also studied.

\section{The study}

All patients detained under Sections 2, 3 or 37 of the Mental Health Act (1983) between February 1994 and February 1995 at the Queen Elizabeth Psychiatric Hospital, Birmingham were studied. Data on age, gender, ethnicity, place of birth. first language, educational background, employment status, psychlatric diagnoses, previous admissions and subsequent admissions were obtained from the patient's medical notes. Data on type of detention; reason for detention; whether the doctors recommending the detention were previously acquainted with the patient; whether the patient or nearest relative appealed against the detention; whether the appeal was heard; whether the patient was discharged by the tribunal; and whether they were subsequently readmitted under the Act, were collected from the hospital records of formal admissions. There were 405 detentions in the defined study period but 
data were available on only 356 (88\%). One hundred and twelve sets of notes selected in numerical order according to the patients' registration numbers were scrutinised in detail for data unavallable from the legal papers.

\section{Findings}

In the study period $182(51.1 \%)$ detentions were under Section 2, $168(47.1 \%)$ under Section 3, and $6(1.7 \%)$ under Section 37. Male patients accounted for $159(44.7 \%)$ detentions and female patients for 197 (55.3\%). The mean age of the detained patients was 41.3 years (s.d.=18.7). There were 126 (35.4\%) appeals, of these 125 were made by the patient and one was made by the nearest relative. Out of the appeals made, 52 (41.3\%) were heard by the MHRT and 18 of these were discharged. Of the 18 patients discharged seven (28.9\%) were re-admitted in the study period, five of whom were admitted under the Act. One hundred and seventy-eight (50\%) detentions were recommended by doctors of whom the non-psychiatrist, namely the general practitioner, was previously acquainted with the patient, and $92(25.8 \%)$ were recommended by doctors of whom the non-psychiatrist was previously unfamiliar with the patient. The other detentions were recommended by two psychiatrists, one or both of whom were previously acquainted with the patient. The reason for the detention was for the patient's own protection in $176(49.4 \%)$ cases and for the protection of the patient and others in 171 (48\%) cases.

There was no statistically significant difference between the mean ages or gender of the patients detained on either Sections 2 or 3. However, all detentions on Section 37 were of male patients. A significantly higher number of patients admitted under Section 2 were not previously acquainted with the non-psychiatrist making the medical recommendation $(P<0.00001)$. The mean age of patients who appealed to the MHRT was 36.6 (s.d.=19.6) years compared with 47.9 (s.d. $=13.9$ ) years for those who did not appeal $(P<0.00001)$. The mean number of previous admissions and subsequent admissions did not differ between those patients who appealed and those who did not. Patients detained for the protection of self and others or solely for the protection of others were more likely to appeal to the MHRT $(P<0.05)$. There were no differences in the mean age, mean number of previous and subsequent admissions, type of Section, or the reason for detention between those patients whose appeals were heard and those whose appeals were not heard. This was also true for the comparison between those patients whose detention was confirmed by the tribunal and those who were discharged by the MHRT.
A more detailed investigation was conducted on 112 patients. Seventy-seven (69\%) had a diagnosis either of major affective disorder or of schizophrenia. There was no statistically significant difference between patients detained on either Sections 2, 3 or 37 in terms of ethnicity. place of birth, marital status, first language, standard of education, employment status or psychiatric diagnoses. The mean number of previous detentions was significantly higher for patients detained on Section $3(P<0.00001)$ and of subsequent detentions was higher for patients detained on Section $2(P<0.01)$. Patients whose first language was not English were significantly less likely to appeal to the MHRT $(P=0.05)$. The mean number of subsequent detentions was significantly greater for those patients who appealed $(P<0.01)$. There was no difference in ethnicity, place of birth, marital status, standard of education, employment status, psychiatric diagnoses between patients whose appeals were heard and those whose appeals were not heard. This was also the case for the comparison between those whose detentions were confirmed by the tribunals and those discharged. In particular, ethnicity did not appear to influence the tribunal's decision whether to discharge or not.

\section{Comment}

We found that there are some differences in the demographic characteristics of patients who appeal to the MHRT when compared with those who do not appeal. Patients who appealed to the MHRT were significantly younger than those who did not. Patients whose first language was not English did not appeal against their detention in the study period. Patients detained solely for the protection of self were less likely to appeal than those detained for the protection of others or for the protection of self and of others. We also found that none of the demographic variables studied including ethnicity was associated with the outcome of the tribunal hearing.

The diagnosis of dementia was confined to the older adult age group and this may in part explain the finding that increasing age was assoclated with the tendency not to appeal against detention as this group may not have been aware of their situation and of their right to appeal. It may also be the case that older patients are less inclined to challenge the views of authority figures. Whatever the case a structural bias against older people appealing against detention may be present and this falling of the appeal system should be recognised.

The proportion of all patients appealing against their detention was $35.4 \%$. If this figure was applied to the eight patients whose first language was not English, approximately three patients 
would have been expected to appeal during the study period, yet none did. There is a well described statutory policy regarding the giving of information to detained patients about their rights and there is special reference to the use of interpreters when giving information to patients. In addition, there are leaflets in languages other than English such as Hindi and Punjabi. Nonetheless, we have shown that patients whose first language is not English did not appeal and the obvious concern is that this is a reflection of lack of understanding of rights or of awareness of these rights. It may be that for all patients whose first language is not English including those whose first language is British Sign Language, a spectal emphasis must be placed on the use of interpreters or mandatory review of detentions.

That patients detained for the protection of others or of self and others were more likely to appeal against their detentions suggests that patients who are severely disturbed are more likely to appeal. This is further amplified by the finding that patients who appeal are more likely to be subsequently detained and that the medical recommendations of these patients were significantly more likely to mention injurious behaviour to others and damage to objects. Patients with psychoses are more likely than other patients to take up the offer of appeal when asked (Stern, 1994) but nonetheless unlikely to be discharged by the tribunal.

The tribunal's decision of whether or not to discharge a patient is supposed to be based on the best interests of the patient and the community at large. However, as with any system there is a potential for bias. It is, therefore, reassuring that in this study there seems to be no apparent bias involving any of the demographic characteristics studied including ethnicity. Thus, MHRTs seem to be a fair system if the opportunity of appeal is taken up. The failing appears to be that not all detained patients have equal access to the appeals system.

\section{References}

Blumenthal, S. \& Wessely, S. (1994) The cost of Mental Health Review Tribunals. Psychiatic Bulletir, 18. 274-276.

Bradley, C., Marshall, M. \& Gath, D. (1995) Why do so few patients appeal against detention under Section 2 of the Mental Health Act? Brttish Medical Journal. 310. 364-367.

KapLAN, C. A. (1995) Mental Health Review Tribunals and the Councll on Tribunals. Psychiatric Bullettr, 19. 438-441.

MALCOLM, M. T. (1994) The cost of Mental Health Review Tribunals [letter]. Psychiatric Bulletin, 18, 577-578.

McClougrun, I. J. (1995) Detention under the Mental Health Act letter]. Psychiatric Bullettr, 19, 514.

PEAY, J. (1989) Tribunals on Trial. Oxford: Clarendon Press.

SAMD. K. F. G. \& SAshmbHaran, S. P. (1992) Mental Health Review Tribunals. Psychiatric Bullettr, 16, 470-472.

STERN, R. S. (1994) The cost of Mental Health Review Tribunals [letter]. Psychiatric Bullettn, 18, 578.

Miranda Shah, Medical Student; and Femi Oyebode*, Consultant Psychiatrist and Senior Clinical Lecturer, Queen Elizabeth Psychiatric Hospital, Mindelsohn Way, Edgbaston, Birmingham B15 $2 Q Z$

*Correspondence 